
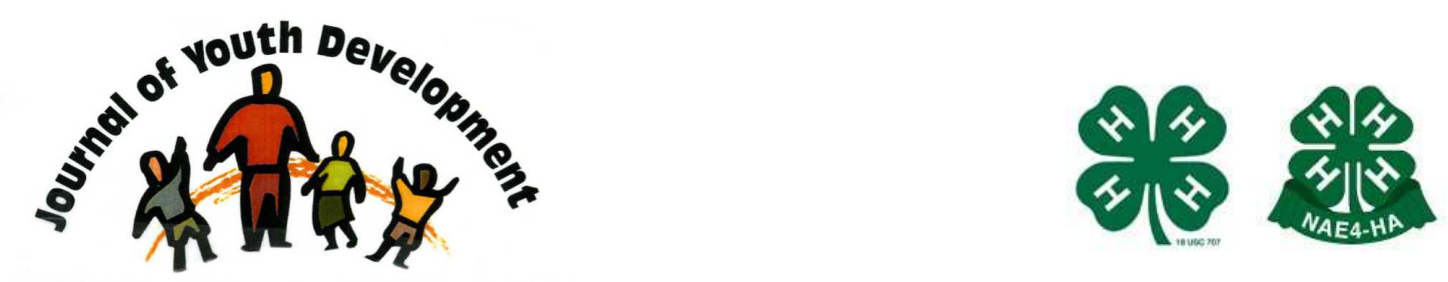

Bridging Research \& Practice

\title{
Educator Perceptions of Conflict Interactions Among Young Children in Inner-city Elementary and Middle Schools
}

\author{
Jonathan Huff \\ Antioch University McGregor \\ Youngstown, $\mathrm{OH}$ \\ ffuhj@hotmail.com \\ Victor R. Wilburn \\ Southeast Missouri State University \\ Cape Girardeau, MO \\ wilburn@semo.edu \\ Getinet Belay \\ Antioch University McGregor \\ Yellow Springs, $\mathrm{OH}$ \\ gbelay@mcgregor.edu
}




\title{
JOURNAL OF YOUTH DEVELOPMENT \\ bridging research and practice

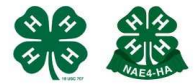

Volume 4, Number 3, Fall 2009

Article 090403FA006

\section{Educator Perceptions of Conflict Interactions Among Young Children in Inner-city Elementary and Middle Schools}

\author{
Victor R. Wilburn \\ The University of Akron \\ Jonathan Huff and Getinet Belay \\ Antioch University McGregor
}

\begin{abstract}
A study that investigated the perceptions of educational professionals regarding the rising issue of aggressive and disruptive behaviors among young children in inner-city schools is discussed in this article. A convenient sample of 14 professionals were selected and interviewed from educators in an inner-city located in the northeast region of Ohio. Evidence of this investigation suggests that young children's aggressive behaviors are increasing in both occurrence and complexity. While these behaviors are perceived to be a function of certain environmental exposures, a case can be made for the effectiveness in conflict management and life skill application in young children as many children seem to display more problems in collective and social settings.
\end{abstract}

\section{Introduction}

Conflict between people represents one of the most basic and common forms of human interactions. Perhaps, what is most vital to the integrity of the individual and the respective community is the manner in which these conflicts occur. While there is overwhelming precedence for viewing conflict in a negative manner, it is clear that this behavior among young children is often symptomatic of dysfunction within respective families and communities (Fonzi, Schneider, Tani, \& Tomada, 1997; Hughes, Gleason, \& Zhang, 2005; Rinaldi \& Howe, 2003). In consort, these behaviors often represent the collective experiences that children witness and experience from their respective environments. Consequently, nowhere is this issue more prevalent than in the school system where children's collective behaviors are often a reflection of their perceived experiences in the family and the community settings. 
Rinaldi and Howe (2003) employed a systems approach to understanding the relationship between conflict and behavioral outcomes. The researchers purported that perceived conflictual interactions in one setting or subsystem (i.e., family setting) can influence how children perceive conflict and behavioral responsiveness in other settings (i.e., school settings). A similar systematic approach is employed by researchers (McDonald, Jouriles, Briggs-Gowan, Rosenfield, \& Carter, 2007; Yates, Dodds, Sroufe, \& Egeland, 2003) who provide support to the position that early childhood exposure to violence may in fact be a catalyst to producing emotional and behavioral problems in children by affecting their internal regulating abilities.

According to Brotman, Gouley, Chesir-Teran, Dennis, Klein, and Shrout (2005), socially deviant and aggressive behaviors exhibited by adolescents and adults can be traced back to aggressive and behavioral disturbances as early as the elementary year of children's development. Similarly, environmental factors such as inner-city poverty and stress tend to produce behavioral disturbances and adjustment problems in the form of aggression that can be identified as early as infancy and toddlerhood and as late as adolescence (Squies, J. \& Nickel, R., 2003; McDonald, Joriles, Briggs-Gowan, Rosenfield, \& Carter, 2007). Given such a range of developmental consequences due, in part, to the stressors associated with poverty and developmentally inappropriate communities, it is evident that a closer look at children's behaviors may provide insight on children's developmental challenges and subsequent needs.

In the United States, professionals in the school system are plagued with the rising incident of conflicts (bullying, fighting, and physical/verbal abuse) exhibited by students (Brinson et al., 2004; Palmar, 2001; Tidwell, Flannery, \& Lewis-Palmer, 2003; Pietrzak, Petersen, \& Speaker, 1998; Wager, 1993). According to some researchers (Johnson \& Johnson, 1995; Tidwell, Flannery, \& Lewis-Palmer, 2003), many students feel that school is an unsafe environment and this can hinder student's learning outcomes. What was once a distant topic of discussion in academic classes of history and social studies is now the witnessed account of many children as they experience increasing incidents of violence in their communities and schools (Pietrzak, Petersen, \& Speaker, 1998; Singer, Miller, Guo, Flannery, Frierson, \& Slovak, 1999). How some students problem-solve and manage future conflicts are of great concern to teachers and administrators throughout schools (Mavropoulou \& Padeliadu, 2002; Palardy \& Palardy, 2001; Wager, 1993).

\section{Rationale}

In response to the growing occurrence of conflicts among children, schools are implementing a variety of responsive programs to help children resolve conflicts (DuPaul \& Huff, 1998; Tidwell, Flannery, \& Lewis-Palmer, 2003). Increasingly, professionals are discovering that these behaviors represent poor communication skills due to limited interpersonal resources and social skills (Lane, Menzies, Barton-Arwood, Doukas, \& Munton, 2005). Consequently, more needs to be known about the nature of children's conflicts, especially among inner-city children. While a considerable amount of data has been collected to investigate conflict among children, less is known about the nature of conflict and resolution among elementary and middle school students in inner-city communities and from the perspective of educators and administrators.

The purpose of this project is to develop a greater understanding of the specific characteristics of conflict as they relate to inner-city elementary and middle school students (K-8). In consort, a better understanding of conflict among inner-city children can enable professionals to develop a programmatic intervention that is unique to their specific challenges. This project also allows 
for a better understanding of the problems educators face respective to inner-city school systems.

\section{Conflict and the Academic Environment}

Many researchers (Flanagan, Bierman, \& Kam, 2003; Lewis, Colvin, \& Sugai, 2000; Smolkowski, Biglan, Barrera, Taylor, Black, \& Blair, 2005) have provided support to the view that children are not coming to school "skill ready" and are thereby limited when it comes to managing conflicts with their peers. It is clear from the noted researchers that teaching conflict management skills may be just as important as teaching the basic skills of reading, writing, and arithmetic.

Many children are displaying a multitude of problematic behaviors (i.e., overt aggression, verbal altercation, non-compliance) that can affect not only their ability to perform academically, but also, affect their ability to develop appropriate pro-social behaviors. These behaviors often interfere with their ability to develop relationships with teachers and peers which are essential building blocks to later social development (Flanagan, Bierman, \& Kam, 2003). Similarly, researchers (Smolkowski, Biglan, Barrera, Taylor, Black, \& Blair2005) noted these disruptive behaviors also tend to be associated with limited social skills development and can lead to later academic problems beyond the elementary years.

The management of classroom behavior in schools has emerged as a pressing issue facing educators in recent years (Mack, 2004; Palardy \& Palardy, 2001; Rajpal, 2001; Sbarra \& Pianta, 2001; Wager, 1993; Walker \& Holland, 1979). In fact, teachers are increasingly faced with the challenge of dealing with children who have emotional and behavioral problems that present daily challenges in the classroom (Mack, 2004; Rajpal, 2001; Tidwell, Flannery, Lewis-Palmer, 2003; Mavropoulou \& Padeliadu, 2002). Consequently, what seems to be most challenging to this issue is the contagious nature of problematic behaviors in the classroom. According to Boxer, Guerra, Huesmann, and Morales (2005), when children demonstrate continued disruptive and aggressive behaviors, it tends to promote similar behaviors in other children who witness these outbursts in the classroom. Consequently, the frequency of these disruptive behaviors among students of diverse groups tends to result in cognitive and interpersonal deficiencies (Keogh, 2006).

In the midst of such diverse challenges, teachers are also expected to improve their standard of teaching in such a way that it is quantitatively reflected in student academic assessments (Tidwell, Flannery, \& Lewis-Palmer, 2003). According to Souter (2001), physical aggression towards the teacher is a common behavioral problem that educators are challenged to address. Although the degree of problem behaviors may vary from teacher to teacher, educators in general have a concern about the growing trend of disruptive behavior (Rajpal, 2001; Wager, 1993). While these problems of conflict in the classroom are not new, they are increasing in occurrence and complexity. In fact, Walker and Holland (1979) stated:

Observers of the educational process (psychologist, sociologist, journalist, and others) have suggested that the following factors may be instrumental in accounting for such a development: (a) a general erosion of respect for adult authority in our society; (b) the deleterious effects of an increase in television-viewing by children; (c) changes in childrearing practices; (d) an increase in societal discord, including martial conflicts that have a disruptive influence upon the family; and (e) a heightened awareness of and emphasis upon the prerogatives of the individual. 
Although Walker and Holland's article was written in the late seventies, their insight on this issue still has merit and relevance to current behaviors among young children in elementary and middle school. The variables discussed are still mirrored in the modern day classroom as children continue to bring outside influences into the school and the classroom which affects how they problem-solve (Gutman \& McLoyd, 2000; Sheline, Skipper, \& Broadhead, 1994).

In many respects, school-related behavioral problems are simply a reflection of what goes on outside of the school environment (Gutman \& McLoyd, 2000; Sbarra \& Pianta, 2001; Schaeffer \& Rollins, 2001). Similarly, Schaeffer and Rollin (2001) noted that the key to understanding the nature of children's conflict is rooted in their collective environment (i.e., the home, the community, the school, the media). It is for this reason that the systemic and ecological approach of Bronfrenbrenner's Model of Human Development can be an effective model for conceptualizing the nature of conflict in inner city schools and potential methods to resolve the conflict.

\section{Conflict and the Family}

Many researchers (August, Egan, Realmuto, \& Hektner, 2003; Frosch \& Mangelsdorf, 2001) have noted that there is a connection between the quality of the family environment and child adjustment outcomes. When children come from dysfunctional families, children's adjustment outcomes tend to seek expression in the form of aggressive behaviors (Bond \& McMahon, 1984; Erath, Bierman, \& the Conduct Problems Prevention Research Group, 2006; Frosch \& Mangelsdorf, 2001), poor academic performance (Frosch \& Mangelsdorf, 2001; Hughes, Gleason, \& Zhang, 2005), and the inability to form healthy relationships (McDonalds et. al., 2007).

According to Keilty and Galvin (2006), the family represents a vital source of a child's developmental experiences which reflect such skills and traits as temperament, communication style, interactions strategies and even level of interest or engagement. Consequently, children tend to develop in a manner that allows them to cope and manage respective to the challenges of their environment. This is also indicative of the point that children's development might be a reflection of certain limitations in problem-solving, coping, and effective interacting with their peers when they come from family settings where they are exposed to high amounts of conflict and stress. This is especially the case as many children are increasing a product of families where there is stress and conflict due to divorce and single parent households (Chiriboga, Catron, \& Weiler, 2009). The researchers give support to the notion that destabilizing families contribute to destabilizing factors respective to children's development and can put them at risk for social adaptation.

\section{The School Playground}

The school playground has traditionally been a setting that is most problematic regarding the incidence of conflict among children. Borg (1999) purported that both victims and bullies indicated that the school playground was a popular place for bullying. In spite of this, researchers have found that social skills intervention can significantly decrease the occurrence of aggressive acts on the playground (Anderson-Butcher, Newsome, \& Nay, 2003).

Conflict resolution programs have also demonstrated positive outcomes towards reducing aggression on the playgrounds. In fact, Cunningham et al. (1998) indicated that approximately $90 \%$ of the disputes were successfully handled by peer mediators. The researchers also purported that the students frequently practiced their newly acquired mediation skills and frequently employed the services of the student mediation teams. In addition, the number of 
incidents spilling over from the playground to the classroom significantly declined and aggressive behaviors was reduced.

\section{Inner-City School Peer Mediation Program}

The challenge associated with conflict management among inner-city children is especially problematic because of the range and complexity of factors contributing to conflict in inner-city children. Johnson, Johnson, Mitchell, Cotton, Harris, and Louison (1996) investigated the nature of conflict by investigating four specific questions that relate to conflicts elementary students face:

(a) What types of conflicts are mediated by conflict managers?

(b) What strategies do elementary students use to manage conflicts?

(c) What solutions derive from peer mediation? and

(d) Is there a difference between male-male, female-female, and male-female disputes?

According to Johnson et al. (1996), the mediated conflicts generally consisted of relationship problems characterized by physical aggression (hitting, kicking, and physical harassment) and verbal aggression (name calling, insults, and rumors). Once children were attacked, they used verbal or physical aggression to solve their problems. The cases that went to mediation had a $98 \%$ success rate; however, $84 \%$ of the solutions or agreements made by the students had a short-term result. Johnson et al. (1996) also noted that children commonly decided that avoidance was an appropriate solution to the aggressive occurrence.

What we can take away from this research is that there is definitely a need to study the nature of conflict in inner-city schools. After reviewing this literature, it is apparent that conflict resolution programs can be vital in elementary and middle schools, however, by better understanding the nature of conflict, educators are in a better position to determine the appropriate intervention. Many professionals view children's conflicts to be related to a lack of appropriate experiences and resources to effectively problem-solve; consequently, many schools are responding by providing intense and creative classroom teaching and behavioral modification programs to address the issue (Tidwell, Flannery, \& Lewis-Palmer, 2003).

\section{An Ecological Approach to Conflict}

The tenants of systems theory and Bronfrenbrenner's model of human development have been employed because of their holistic approach to understanding children's development. In such an approach, much attention is paid to the symptomatic behaviors and their relation to the structure and organization that exists within a child's life. Given that children are developing from their collective experiences in the home, their community, and in their educational settings, this model is very useful given the context. The ecosystems approach to conflict can be seen in the many researchers (Stouter, 2001) who purport that children's conflict at school is a function of the collective environment. Bronfenbrenner's (1979) model provides precedence for educators by understanding these conflicts from the micro and meso systemic approaches. Consequently, educational leaders can now appropriately contextualize the nature of conflict which can be effective in determining appropriate intervention.

The microsystem is the layer that has direct contact with a child's immediate surroundings. Brinson et al. (2004) noted the importance of understanding that children's modeling of behavior is manifested in later imitative behaviors in the classroom. For example, children raised in environments where they witness multiple acts of violence may be inclined to integrate those behaviors into their personality development and decision making outcomes. 
Consequently, children are likely to exhibit these behaviors in other settings through deferred imitation.

When children begin to integrate these behaviors across multiple settings, they are exhibiting mesosystemic outcomes. According to Bronfrenbrenner (1994), the mesosystem consists of connected experiences and behaviors that are a function of two or more settings within a person's life process (e.g., the relations between home and school, school and workplace, etc.). Therefore, the transmission of life experiences and witnessed behaviors across systems creates mesosystemic outcomes.

The ecosystem reflect two or more environmental settings where at least one of the settings does not directly influence the developing child but does so indirectly (i.e., parent's employment cite or their job stability). This system begins to reflect many unintended outcomes that children often experience which can significantly affect their developmental course.

Bronfrenbrenner's notion of the macrosystem reflects a larger and more collective array of factors indicative of customs, traditions, and values. The macrosystem can arguably be seen as an overall reflection of a child's socialization process which is fundamental to the previously noted systems.

The chronosystem represent Bronfrenbrenner's most recent expansion of the ecological model. This system notes the importance of considering the relations to time and change among people and communities. Similarly, as individuals grow and develop, there are internal and external changes that must be considered when charting one's development.

The way children experience and interpret the world determines their behaviors. The power of an ecological and systems theory approach to conflict is that it gives educators an alternative viewpoint on the complex societal influences they encounter (Souter, 2001). In light of this view, educators are now challenged to explore program development designed to specifically address behaviors influenced, in part, by external sources.

\section{Methodology}

Based on an extensive literature investigation, the researchers surmise that a qualitative based study could provide appropriate insight towards better understanding teacher perceptions of conflict behaviors between elementary and middle school children. Upon approval, interview schedules were conducted for data collection and analysis. The structured interviews were conducted with elementary and middle school teachers, principals/assistant principals, counselors, and school psychologists to represent the professional perspective regarding conflict among young children who reside in inner-city schools.

\section{Procedure}

Prior to beginning this study, a letter of consent sent to the superintendent of the board of education in an inner-city school system of Northeast, Ohio. Once authorization was granted, letters were sent to perspective schools within the district and three schools were selected for investigation (two elementary schools and one middle school). The principals and teachers of these schools were informed of the study and also provided permission of participation in this study. 


\section{Participants}

The participants in this study consisted of 14 school educators (i.e., teachers, administrators, principals/assistant principals, counselors, and school psychologists). The convenient sample of participants came from two elementary schools grades $\left(\mathrm{K}-6^{\text {th }}\right)$ and one middle school that has grades $\left(5^{\text {th }}-8^{\text {th }}\right)$. The administrator (retired superintendent) and school psychologist work with the board of education.

\section{Data Collection}

Adult participants were subjected to face-to-face interviews which consisted of 15 questions regarding conflict among children at school. The questions consisted of both open-ended and structured items surrounding the nature of conflict educators' face with inner-city children in the school/classroom setting. Data was examined to identify common themes reflective of participant opinions, attitudes, and beliefs on the issue. (See Appendix A).

\section{Results}

Participants were asked to identify the behaviors that were deemed most problematic in a given school day. The overwhelming majority purported that children exhibit such aggressive behaviors as talking out of turn, physical and verbal abuse, lack of self-control, bullying, and non-compliance with adult authority. Consequently, these behaviors were often seen as behavioral catalysts to conflict dynamics throughout the school day. In fact, a few of the participants expressed how they felt about these behaviors.

"In the classroom their behaviors range from lack of self-control to having violent behaviors. Talking out in class...aggravating each other... This school year the behavior is very extreme" - 3rd grade teacher

"Student insubordination and conflict between each other are the most problematic. If we don't resolve the conflict verbally, it can escalate into a physical fight." - Principal (grades K-6)

Teachers and administrators were also asked about the frequency, duration, and setting of the incidents. Many participants expressed that the problematic behaviors take place during transition periods throughout the school day (i.e., changing from one class to another or changes within the classroom environment). A general theme noted by the interviewees was that depending on the conflict and circumstance of the dispute, the majority of the participants expressed that they had to stop their lessons to address disputes or correct disruptive behavior most of the time. In fact, one participant noted that she had to address students all of the time, while another teacher stated that she has to stop her lessons at least once a week. However, none of the participants noted that they never have to stop their lessons to address disputes.

Although the manner in which teachers are faced with disputes differ, it is clear that there are common themes which can be deduced from their interactions. For example, several participants indicated that their initial response conflict or disruptive behavior came in the form of verbal warnings. A few participants stated:

"First, I'll give the student a verbal warning, second verbal warning, and third I will tell the student what he/she is going to do."- Administrator ex-superintendent 
"When I can't ignore the problem anymore, I challenge the child verbally" $-5^{\text {th }}, 6^{\text {th }}$, and $8^{\text {th }}$ grade teacher

Typically, the teachers in this study would give verbal warnings to the children at the onset of conflict or a dispute, whereas administrators (principals, assistant principals) ask more questions to figure out the root causes of the conflict. Of the 14 participants, $50 \%$ purported that they do get upset over the conflict they encounter. In that, many participants stated that they get upset over the conflict because they had to stop the class lesson to address the conflicting situation.

Another question asked participants to describe how they handle the dispute or conflict situation and explored the methods of interventions used when the conflict occurs. Most teachers purported that a common technique was to remove the child from the classroom setting if a conflict escalates. This was often done as a short term response until a later intervention could be initiated. For instance, the teacher may call the parent and ask for the parent to come in to talk about the child's behavior.

Participants also noted that while parents generally seem supportive when they call to inform them about their child's behavioral problems, many teachers questioned the parent's reinforcement with the children once in the home environment. In fact, some parents seemed not to care at all which is noted in the relatively low participation rates of parents at parent/teacher conferences and the difficulty of getting in touch with parents to address the issue. This finding is extremely important because some researchers (Klein \& Forehand, 2000) purport that parental responsiveness to children's behaviors was a key influence towards reducing disruptive behaviors in inner-city school systems.

Of the 14 participants in this study, over half believed that their methods of interventions work to control disputes or disruptive behaviors. Six participants felt their methods work most of the time. None of the participants expressed that their methods never worked. When the participants were asked whether the conflict was resolved once it reaches an administrative level within the schools? 12 of the participants felt that most of the times, the administration handles the problem. A reason why the administration does a good job with handling disputes occurs because both principals from the elementary schools in this study use the Baldrige System (Borawski and Brennan, 2008) as a way to be consistent with the children. By having a system wide approach, the children learn how to manage behavior because they have a system to follow. However, if a principal has a problem with a child, they can use creative measures.

When the participants were asked if they have to address a particular student or students over and over again about their behavior, four responded that they have to address the same students all of the time. Nine reported that they address the same student most of the time. In fact, the school psychologist in this study stated that $75 \%$ of the time, the same children returned to see her. The correlation between short-term resolutions by the administration and educators having to address a particular student or students is evident in this study.

The overwhelming majority of teachers and professionals indicated that they noticed a change in the conflictual behaviors in children throughout their experience teaching. In fact, many purported that the following behaviors have changed considerably in children:

- More aggression/physical and verbal abuse

- Gross Insubordination 
- Lack of self-respect for themselves and other children

- Lack of respect for adults

- Lack of communication between teacher and student

The general feeling the many teachers and school professionals noted was that the problem behaviors exhibited by children was due in part to frustrations in children due to their unstable and non-traditional home environments (i.e., single-parent households, families of children with different fathers). The solutions that participants gave hit on many issues such as having more community support, counseling in the elementary schools, and collaborative workshops with parents, teachers, and the broader community in order to build trust and consistent involvement in the lives of children.

This study also shows that the participants feel that conflict resolution skills can change the climate of a school or learning environment. In their opinion, the school system has done a good job of giving workshops on conflict resolution to teachers, but not much has been done with children and parents. Also, more long-term training is needed, in which everyone embraces the concept of conflict resolution.

\section{Discussion \& Implications for the Future}

In many ways, the problems that young children exhibit is a reflection of their witnessed experiences in consort with the resources they have to cope with the challenges associated with interacting in their broader community. Clearly, some inner-city families and communities are not preparing children with basic life application skills and this may explain why children are unable to meet the expectations of an academic environment (Sheline, Skipper, \& Broadhead, 1994). Arguably, the environments that some children are a part of may explain certain skill deficits experienced by many inner-city children. Similarly, Snyder, Cramer, Afrank, and Patterson (2005) recommended caution towards generalizations suggesting that aggressive behaviors among children are exclusively associated with the child's family and home environment. Instead, it is important to also consider other factors that can affect children (i.e., peer pressure, community witnessed violence).

According to Lane, et al., (2005), it is vital that professionals implement programs that facilitate greater social development. Because the responsibility of children's development must be seen as a shared responsibility, professionals within the inner-city school systems may be challenged to think outside of the box in order to better prepare children for success. For example, school systems might consider developing more classes in the areas of life skills and conflict mediation development. These classes should be considered as prerequisites to traditional classes once children have demonstrated a certain degree of problem behaviors within the school system. While this may considerably delay the academic progress of some children, it may considerable reduce the alarming incidents of aggression and school drop-outs that we are seeing during later development.

In addition, little to no programmatic intervention exists in elementary school systems for the purpose of addressing the issue of aggression and conflict resolution (Dale, 1998). It is imperative that professionals begin to see aggression as a reflection of social skill development and begin to develop programs during the elementary years while children are impressionable. These programs can also help children to better understand and cope with their changing environment and interactions. In turn, this can bring us closer to making children's environments more safe and predictable; thus making them ready to learn. 
Research clearly indicates that children are increasingly challenged to focus on learning in educational settings that are hostile and unsafe. In addition, teachers are increasingly challenged to teach to curriculum while at the same time manage the increasing disruptions associated with young children in inner-city schools (Tidwell, Flannery, \& Lewis-Palmer, 2003).

\section{Limitations to Study}

Because this study is a pilot investigation, a small sample of participants was solicited for insight into the issue of conflict among elementary school children. Also, the interview questions were general and open-ended to get at the full range of professional opinions of the participants, however, the scope of generalizability may in part be affected. The researchers intend to use the findings of this pilot investigation to develop and evaluate programmatic intervention models which can be employed to enhance children's problem-solving skills and improve teacher-student interactions in the classroom.

\section{References}

Anderson-Butcher, D., Newsome, S., \& Nay, S. (2003). Social skills intervention during elementary school recess: A visual analysis. Children \& Schools, 25(3), 135-146.

Bond, C.R. \& McMahon, R.J. (1984). Relationships between marital distress and child behavior problems, maternal personal adjustment, maternal personality, and maternal parenting behavior. Journal of Abnormal Psychology, (93)3, 348-351.

Borawski, P. \& Brennan, M. (2008). The Baldridge Model: An Integrated and Aligned Systems Approach to Performance Excellence. Journal of Association Leadership.

Borg, M. (1999). The extent and nature of bullying among primary and secondary school children. Educational Research, 41, 137-153.

Boxer, P., Guerra, N., Huesmann, L., \& Morales, J. (2005). Proximal peer-level effects of a small-group selected prevention on aggression in elementary school children: An investigation of the peer contagion hypothesis. Journal of Abnormal Child Psychology, 33(3), 325-338.

Brinson, J.A., Kottler, J.A., \& Fisher, T.A. (2004). Cross-cultural conflict resolution in the schools: Some practical intervention strategies for counselors. Journal of Counseling and Development, 82, 294-301.

Bronfenbrenner, U. (1994). Ecological models of human development. International Encyclopedia of Education, Vol. 3, (2 ${ }^{\text {nd }}$ Ed.). 1643-1647.

Bronfenbrenner, U. (1979). The ecology of human development. Richland, Washington: Performance Associates.

Brotman, L.M., Gouley, K.K., Chesir-Teran, D., Dennis, T., Klein, R.G., \& Shrout, P. (2005). Prevention for preschoolers at high risk for conduct problems: Immediate outcomes on parenting practices and child social competence. Journal of Clinical Child and Adolescent Psychology, 34(4), 724-734. 
Chiriboga, D., Catron, L., \& Weiler, P. (1987). Childhood stress and adult functioning during marital separation. Family Relations, 36(2), 163-167.

Cunningham, C.E., Cunningham, L.J., Martorelli, V., Tran, A., Youngs, J. \& Zacharias, R. (1998). The effects of primary division, student-mediated conflict resolution programs on playground aggression. Journal-of-Child-Psychology-and-Psychiatry-and-Allied-Disciplines, 39(5), 653-662.

DuPaul, G., \& Hoff, K. (1998). Reducing disruptive behavior in general education classrooms: The use of self-management strategies. School Psychology Review, 27(2), 290-304.

Erath, S., Bierman, K., \& the Conduct Problems Prevention Research Group. (2006). Aggressive marital conflict, maternal harsh punishment, and child aggressive-disruptive behavior: Evidence for direct and mediated relations. Journal of Family Psychology, 20(2), 217-226.

Flanagan, K.S., Bierman, K.L., \& Kam, C. (2003). Identifying at-risk children at school entry: The usefulness of multibehavioral problem profiles. Journal of Clinical Child and Adolescent Psychology, 32(3), 396-407.

Fonzi, A., Schneider, B., Tani, F., \& Tomada, G. (1997). Predicting children's friendship status from their dyadic interaction in structured situations of potential conflict. Child Development, 68(3), 496-506.

Frosch, C.A., \& Mangelsdorf, S.C. (2001). Marital behavior, parenting behavior, and multiple reports of preschoolers' behavior problems: Mediation or Moderation? Developmental Psychology, 37(4), 502-519.

Gutman, L., \& McLoyd, V. (2000). Parents' management of their children's education within the home, at school, and in the community: An examination of African-American families living in poverty. The Urban Review, 32(1), 1-24.

Hughes, J.N., Gleason, K.A., \& Zhang, D. (2005). Relationship influences on teachers' perceptions of academic competence in academically at-risk minority and majority first grade students. Journal of School Psychology, 43, 303-320.

Johnson, D.W., \& Johnson R. (1995). Teaching students to be peacemakers: Results of five year research. Journal of Peace Psychology, 1(4), 417-438.

Johnson, D.W., Johnson, R., Dudley, B., \& Acikgoz, K. (1994). Effects on conflict resolution training on elementary school students. The Journal of Social Psychology, 134, 803-817.

Johnson, D., Johnson, R., Dudley, B., \& Magnuson, D. (1995). Training elementary school students to manage conflict. The Journal of Social Psychology, 135(6), 673-686.

Johnson , D., Johnson, R., Michell, J., Cotton, B., Harris, D., \& Louison, S. (1996). The effectiveness of conflict resolution managers in an inner-city elementary school. Journal of Educational Research, 89(5), 280-285.

Keilty, B., \& Galvin, K. M. (2006). Physical and social adaptations of families to promote learning in everyday experiences. Topics in early childhood special education, 26(4), 219-233. 
Keogh, H. (2003). Understanding child temperament can have far-reaching impact on behavior and quality of life. The Brown University: Child and Adolescent Behavior Letter.

Klein, K., \& Forehand, R. (2000). Family processes as resources for African American children exposed to a constellation of sociodemographic risk factors. Journal of Clinical Child Psychology, 29(1), 53-65.

Lane, K., Menzies, H., Barton-Arwood, S., Doukas, G., \& Munton, S. (2005). Designing, implementing, and evaluating social skills interventions for elementary students: Step-by-step procedures based on actual school-based investigations. Preventing School Failure, Winter, 1826.

Lewis, T., Colvin, G., \& Sugai, G. (2000). The effects of pre-correction and active supervision on the recess behavior of elementary students. Education and Treatment of Children, 23(2), 109121.

Lupton-Smith, H.S., \& Carruthers, W.L. (1996). Conflict resolution as peer mediation: Programs for elementary, middle and high school students. School Counselor, Vol. 43(5), 374-391.

Mack, K. (2004). Explanations for conduct disorder. Child \& Youth Care Forum, 33(2), 95-113.

Mavropoulou, S., \& Padeliadu, S. (2002). Teachers' causal attributions for behaviour problems in relation to perceptions of control. Educational Psychology, 22(2), 191-202.

McDonald, R., Jouriles, E.N., Briggs-Gowan, M.J., Rosenfield, D., \& Carter, A.S. (2007). Violence toward a family member, angry adult conflict, and child adjustment difficulties: Relations in families with 1 to 3 year-old children. Journal of Family Psychology, 21(2), 176-184.

Palardy, J., \& Palardy, T. (2001). Classroom discipline: Prevention and intervention strategies. Education, 108(1), 87-92.

Palmer, J. (2001). Conflict resolution: Strategies for the elementary classroom. The Social Studies, 92(2), 65-68.

Rajpal, P. (2001). Seriousness of behavior problems of elementary school boys. Education, 4651.

Rinaldi, C., \& Howe, N. (2003). Perceptions of constructive and destructive conflict within and across family subsystems. Infant and Child Development, 12, 441-459.

Sbarra, D., \& Pianta, R. (2001). Teacher ratings of behavior among African-American and Caucasian children during the first two years of school. Psychology in the Schools, 38(3), 229238.

Sellman, E. (2002). Peer mediation, school culture, and sustainability. Pastoral Care in Education, 20(2), 7-11.

Sheline, J., Skipper, B., \& Broadhead, E. (1994). Risk factors for violent behavior in elementary school boys: Have you hugged your child today? American Journal of Public Health, 84(4), 661-626. 
Singer, M., Miller, D., Guo, S., Flannery, D., Frierson, T. \& Slovak, K. (1999). Contributors to violent behavior among elementary and middle school children. Pediatrics, 104(4), 878-884.

Smolkowski, K., Biglan, A., Barrera, M., Taylor, T., \& Blair, J. (2005). Schools and homes in partnership (SHIP): Long-term effects of a preventive intervention focused on social behavior and reading skill in early elementary school. Prevention Science, 6(2), 113-125.

Snyder, J., Cramer, A., Afrank, J. \& Patterson, G. (2005). The contributions of ineffective discipline and parental hostile attributions of child misbehavior to the development of conduct problems at home and school. Developmental Psychology, 41(1), 30-41.

Souter, K.R. (2001). The relevance of systems theory for teachers dealing with emotional and behavioral problems in schools. Pastoral Care in Education, 19 (1), 36-41.

Squires, J., \& Nickel, R. (2003). Never too soon: Identifying social-emotional problems in infants and toddlers. Contemporary Pediatrics, 3(117).

Tidwell, A., Flannery, B., \& Lewis-Palmer, T. (2003). A description of elementary classroom discipline referral patterns. Preventing School Failure, 18-26.

Wager, B. (1993). No more suspension: Creating a shared ethical culture. Educational Leadership, 6, 34-37.

Walker, H.M., \& Holland, F. (1979). Issues, strategies, and perspectives in the management of disruptive child behavior in the classroom. Journal of Education, 161, 25-50.

Yates, T.M., Dodds, M.F., Sroufe, L.A., \& Egeland, B. (2003). Exposure to partner violence and child behavior problems: A prospective study controlling for child physical abuse and neglect, child cognitive ability, socioeconomic status, and life stress. Developmental Psychology, 15, 199-218.

(C) Copyright of Journal of Youth Development $~$ Bridging Research and Practice. Content may not be copied or emailed to multiple sites or posted to a listserv without copyright holder's express written permission. However, users may print, download or email articles for individual use. 


\section{APPENDIX A}

Interview Instrument

Grade:

Years of Teaching Experience:

\section{Capstone Interview Question}

1) What behaviors are most problematic or cause the most conflict throughout the school day?

2) How often does this behavior occur, how long does it last and in what setting does the conflict/dispute take place?

3) How often do you find yourself stopping the lesson to address disputes between classmates or disruptive behavior? (Circle One)

- All of the time

- Sometimes

- Never

- Other....Explain

4) What is your initial response to the conflict/disruptive behavior? Do you find yourself getting upset

5) How do you handle the dispute or conflict situation? Do you find yourself using the same methods of intervention? .

6) In your opinion, does your method of intervention work to control disputes/disruptive behavior in the classroom? (Circle One)

- All of the times

- Sometimes

- Never

- Other...Explain

7) Do you find yourself addressing a particular student(s) over and over again about disruptive behavior? (Circle One)

- All of the times

- Sometimes

- Never

- Other...Explain

8) In your teaching experience, have you noticed a change in the types of behavior that take place in your school?

9) What do you think contributes to this change in behavior? Television... the types of music the children listen too.

10) In your opinion what should be done to correct this problem.... Please give some suggestions. 
11) How does the administration act as a support system for the teachers when a conflict is brought to their attention?

12) Is the conflict resolved once it reaches an administrative level within the school? (Circle One)

- All of the times

- Sometimes

- Never

- Other...Explain

13) Do you ever have to call a parent about their child's behavior? What is their response to the call?

14) Do you find that parents are supportive of you when you call their home? (Circle One)

- All of the times

- Sometimes

- Never

- Other...Explain

15) Do you think conflict resolution skills can change the climate of the school or classroom environment?

Additional Comments: 